\title{
PEROXIDASE PRODUCTION BY CELL SUSPENSION AND HAIRY ROOT CULTURES OF HORSERADISH (ARMORACIA RUSTICANA)
}

\author{
M. PARKINSON*, T. COTTER and P.J. DIX** \\ Dept of Biology, St Patricks College, Maymooth, Co Kildare (Ireland)
}

(Received June 1st, 1989)

(Revision received October 9th, 1989)

(Accepted October 9th, 1989)

\begin{abstract}
The potentual of cell suspension and 'hairy root' cultures of horseradish for production of peroxidase was assessed and the factors limiting production in culture were examined. Peroxidase activity is closely related to growth in both cell suspension cultures and 'hairy root' cultures of horseradish. Under the growth conditions used in the present study however, cell suspension cultures produce twice the total activity of 'hairy root' cultures, and up to $8 \%$ of this activity is released into the culture filtrate at high specific activity. The growth and peroxidase activity of cell suspension cultures are limited by both phosphate and sucrose and the rate of oxygenation of the culture is critical for maximising growth rate, biomass accumulation and peroxidase activity. The isoelectric focussing banding pattern of peroxidase from the 'hairy root' cultures was identical with commercally available horseradish peroxidase whilst that from cell suspension cultures differed with an additional two bands at high $\mathrm{pI}$.
\end{abstract}

Key words: peroxidase; cell suspension; 'hairy root'; horseradish; Amoracia rusticana

\section{Introduction}

Studies on the production of fine chemicals by plant cell cultures have traditionally concentrated on the secondary metabolites used by the food and pharmaceutical industries. Recently however, the attractions of producing valuable enzymes from plant tissue cultures have become evident, and the production of peroxidase from cultures of horseradish has been reported by several workers [1-3].

The enzyme is currently extracted from the roots of field-grown horseradish plants, grown mostly in the tropics, and consequently its production suffers from the uncertainty of the climate. Extraction is also hampered by the coarse, fibrous nature of the plant material and the high levels of acrid allyl isothiocyanates present.

Plant peroxidases are however produced in undifferentiated cells maintained in culture to specific and

\footnotetext{
*Present address: School of Biological Sciences, Dublin City University, Dublin, Ireland.

***To whom reprint requests should be addressed.
}

total activities which may surpass that of the root [4].The ease of handling of the cultures, the possibility that a proportion of the enzyme may be secreted, the suppression of secondary metabolism, and the possibility of an inherently high level of productivity in cell suspension cultures suggest that these cultures could provide an attractive system for commercial scale extraction of peroxidase.

In horseradish, production of peroxidase has been demonstrated in callus [2], and in cell suspension culture $[1,3]$. The latter workers suggested that peroxidase production could be enhanced by callus screening to obtain high-producing lines. One important conclusion from their work was that the slow rate of cell division in culture is a major barrier to commercial exploitation of the technique. However, the authors did not establish the constraints to biomass growth. Furthermore, they did not investigate production in "hairy root" cultures, a fast growing and potentially productive system of culture [5]. This would be an attractive approach to the production of horseradish peroxidase since the enzyme is produced in the root in the intact plant and transfor- 
mation of horseradish by Agrobactenum rhizogenes to produce "hairy root" cultures has already been reported as a micropropagation system [6], thus facilitating its exploitation.

\section{Materials and Methods}

All materials were obtained from Sigma Chemical Company Ltd. (Poole, U.K) except for Murashige and Skoog Plant Salts Mixture which was obtained from Flow Labs (Irvine, Scotland) and Biorad Protein Reagent which was obtained from Bio-rad Laboratories (Caxton Way, Watford). Isoelectric focussing reagents were obtained from Pharmacia.

Seeds of horseradish were obtained locally from Mackey Seeds, (Dublin, Ireland ). These were surface sterilised in $70 \%$ Ethanol for $20 \mathrm{~s}$ followed by a $10 \%$ solution of Domestic Bleach (Domestos) for $10 \mathrm{~min}$, washed in three changes of sterile distilled water and germinated on Murashige and Skoog medium [7] with $3 \%$ sucrose (designated RM) solidified with $0.7 \%$ Difco Bactoagar. After emergence of the second pair of leaves the nodal cuttings were transferred to fresh medium, and subcultured at intervals of eight weeks.

Callus was raised by culturing leaf pieces of nodal cuttings on solidified RM supplemented with $5 \mathrm{mg} / 1$ 2,4-dichlorophenoxy acetic acid and $0.1 \mathrm{mg} / \mathrm{l}$ kinetin (designated 5D). These were subcultured at intervals of four weeks and friable pieces introduced into liquid 5D medium to initiate cell suspensions. These were subcultured at a dilution of 1 part suspension: 3 parts fresh $5 \mathrm{D}$ medium every week. For assessment of growth kinetics, nutrient uptake and the effect of the volumetric mass transfer coefficient $\left(k_{1} a\right)$ on growth, suspensions in late exponential phase were vacuum filtered and subcultured into $50 \mathrm{~cm}^{3} 5 \mathrm{D}$ at a final concentration of $25 \mathrm{~g} / \mathrm{l}$ fresh weight.

'Hairy root' cultures were produced essentially as described previously [8] by inoculation of the petiole of nodal cuttings with a suspension of Agrobacterium rhizogenes at $10^{7} / \mathrm{cm}^{3}$. A. rhizogenes strain LBA 9402 harbouring the binary vector $\mathrm{pBin} 19$ [9] was the kind gift of Dr. John Hamill (Food Research Institute, Colney Lane, Norwich, U.K). Control cultures in which the bacterial suspension was filter sterilised through a $0.22 \mu \mathrm{M}$ pore Milipore filter prior to inoculation did not produce callus or roots from the site of infection nor were roots ever observed on petioles under any other conditions. 'Hairy root' cultures were established by excising the site of infection together with $\mathrm{lcm}$ on either side of the wound and incubating this in liquid RM medium on an orbital shaker. $500 \mathrm{mg} / \mathrm{l}$ Ampicillin was used for three subculture cycles to prevent growth of the bacteria after which the Ampicillin could be removed. 'Hairy root' cultures were characterised by a rapid growth and did not exhibit a strong geotropism.

The growth of cultures was monitored by fresh weight (determined from vacuum-filtered cells), protein (measured by the micro-assay according to $\mathrm{Bi}$ orad) and packed cell volume (determined as previously described [10]).

To assay peroxidase, the culture filtrate was removed by vacuum filtration and assayed directly. To assay peroxidase that was cell-associated, $500 \mathrm{mg}$ fresh weight of vacuum-filtered cells plus $500 \mathrm{mg}$ of acid washed sand was rapidly ground for $60 \mathrm{~s}$ in a mortar with $10 \mathrm{~cm}^{3}$ of $10 \mathrm{mM}$ phosphate buffer (PH 6.2) containing $150 \mathrm{mM} \mathrm{NaCI}$ (PBS). The extract was then made up to $50 \mathrm{~cm}^{3}$ with PBS and centrifuged at $1000 \mathrm{~g}$ for $10 \mathrm{~min}$ to remove cell debris. The supernatant was decanted and assayed. Peroxidase was assayed at $20^{\circ} \mathrm{C}$ as previously described [11] using $0.125 \mathrm{mM}$ dimethoxy benzidine and 0.8 $\mathrm{mM}$ hydrogen peroxide in PBS. Activity was determined by monitoring the change in absorbance at $410 \mathrm{~nm}$ upon addition of $10 \mu \mathrm{l}$ of enzyme solution.

Isoelectric focussing of peroxidase was performed as previously described [12] with the modification that a $1 \%$ agarose gel ( Zeroelectro-osmosis grade) was used instead of acrylamide. Cell extracts and culture filtrates were centrifuged at $10000 \mathrm{~g}$ for 20 $\mathrm{min}$, the supernatant made up to $60 \% \mathrm{v} / \mathrm{v}$ acetone, and proteins precipitated overnight at $4^{\circ} \mathrm{C}$. The proteins were pelleted by centrifugation at $10000 \mathrm{~g}$ for $20 \mathrm{~min}$. The supernatant was discarded, the pellet washed once with PBS, and then resuspended in PBS. The peroxidase activity of each sample and standard was then measured and each diluted with PBS to give a final concentration of peroxidase of $5 \mu \mathrm{g} / \mathrm{cm}^{3}$. These were applied to the isoelectric focussing gel in strips of Whatman Number 1 filter paper for 30 minutes after which the filter paper 
wicks were removed. The calculated loading of peroxidase per lane was $200 \mathrm{ng}$. Peroxidase isozymes were visualised by using an agarose overlay containing $2.5 \mathrm{mM} \mathrm{H}_{2} \mathrm{O}_{2}$ and $1.75 \mathrm{mM}$ dimethoxy benzidine.

Carbohydrate was determined by the phenol/sulphuric acid method [13], phosphate by the phosphomolybdate method [14], Ammonium by Nesslers reagent [15] and Nitrate by nitration of brucine [16]

The Volumetric Oxygen Mass Transfer Coefficient $\left(k_{1} a\right)$ was determined as previously described [17] with the modification that oxygen depletion was by purging with nitrogen. At set time intervals after the onset of aeration, medium was carefully decanted and the percentage oxygen determined using a Clark type oxygen electrode.

\section{Results}

Previous research had shown that peroxidase production in culture was related to growth [1]. Figure 1 shows that growth, as measured by fresh weight and protein accumulation, is closely associated with peroxidase production, in both cell suspension and 'hairy root' cultures . However, the maximum total activity per litre in cell suspension cultures of $1.2 \times 10^{6} \Delta \mathrm{A} / \mathrm{min} / \mathrm{l}$ is almost twice that of the "hairy root' cultures at $0.64 \times 10^{6} \Delta \mathrm{A} / \mathrm{min} / \mathrm{l}$ and the specific activity of the enzyme from cell suspension cultures is also higher than that from the 'hairy root' cultures at $1200 \Delta \mathrm{A} / \mathrm{min} / \mathrm{mg}$ protein and $600 \Delta \mathrm{A} / \mathrm{min} / \mathrm{mg}$ protein respectively. The growth rate of the cell suspensions is however slower than the 'hairy root' cultures with mean cell doubling times through the exponential phase of culture of 5.5 days and 4 days, respectively, and the final biomass accumulation is only two thirds that of the "hairy root's.

Peroxidase is released into the culture filtrate from both 'hairy root' and cell suspension cultures (Fig. 2). Release from 'hairy root' cultures probably results from the initial cut injury prior to subculture as there is little change in activity throughout the growth cycle and the specific activity of peroxidase in the culture filtrate matches that of peroxidase which is cell-associated. In contrast, in the cell suspension cultures, peroxidase is released continuously over the growth cycle to up to $8 \%$ of the total

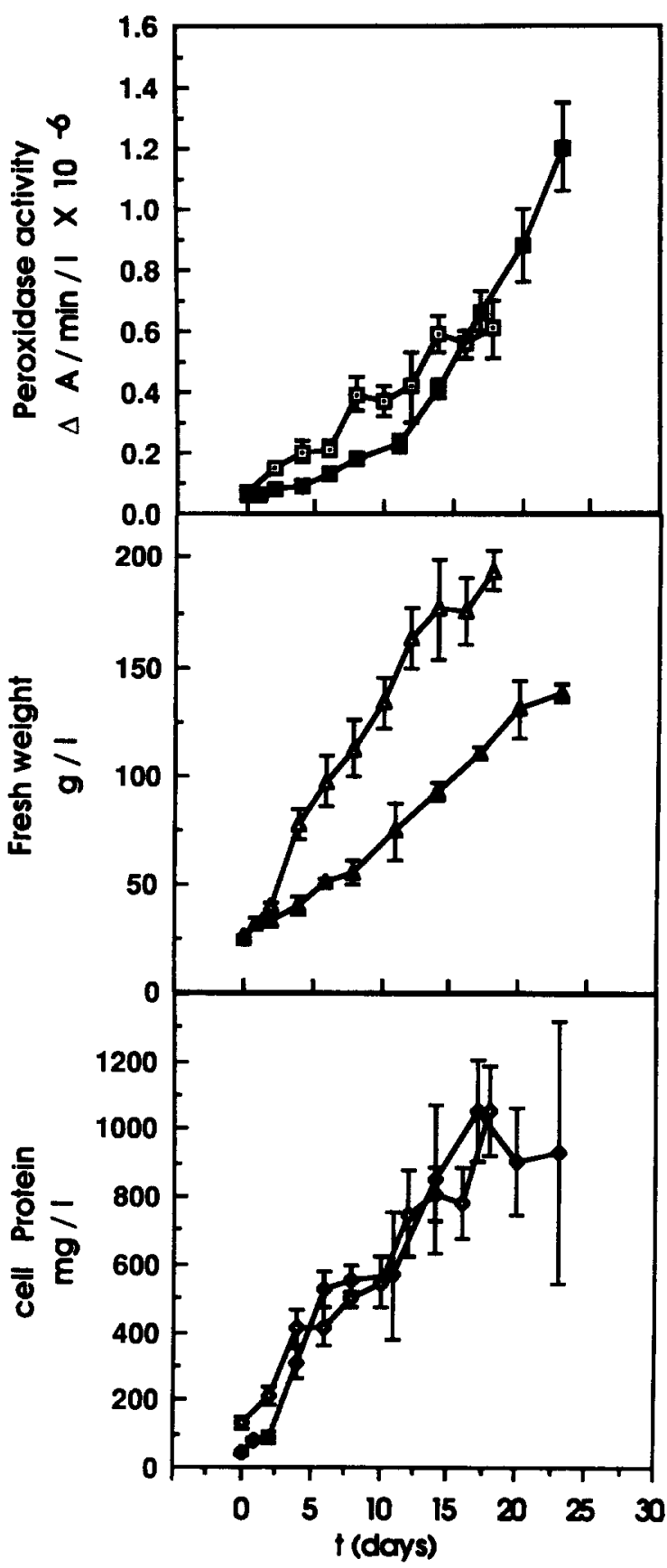

Fig. 1. The increase in peroxidase activity $(\square, \square)$, fresh weight $(\Delta, \Delta)$ and protein $(\bullet, \diamond)$ with tume of culture in cell suspension cultures (closed symbols) and in 'hairy root' cultures (open symbols). Each point is the mean of at least five replucates and is shown with the standard error of the mean. 
activity in the culture and at a relatively high specific activlty of $2500 \Delta \mathrm{A} / \mathrm{min} / \mathrm{mg}$ protein .

Given that peroxidase activity is related to growth, it is important to maximise both the final biomass accumulation and the specific growth rate in the cultures. This objective was addressed in several additional studies on the growth of cell suspension cultures.

Given sufficient space, cell suspension cultures will grow until limited by the exhaustion of critical nutrients. Previous research has shown that phosphate [18], carbohydrate [19], nitrate [20], and ammonia [21] may all limit growth either singly or in combination $[22,23]$. The concentration of these

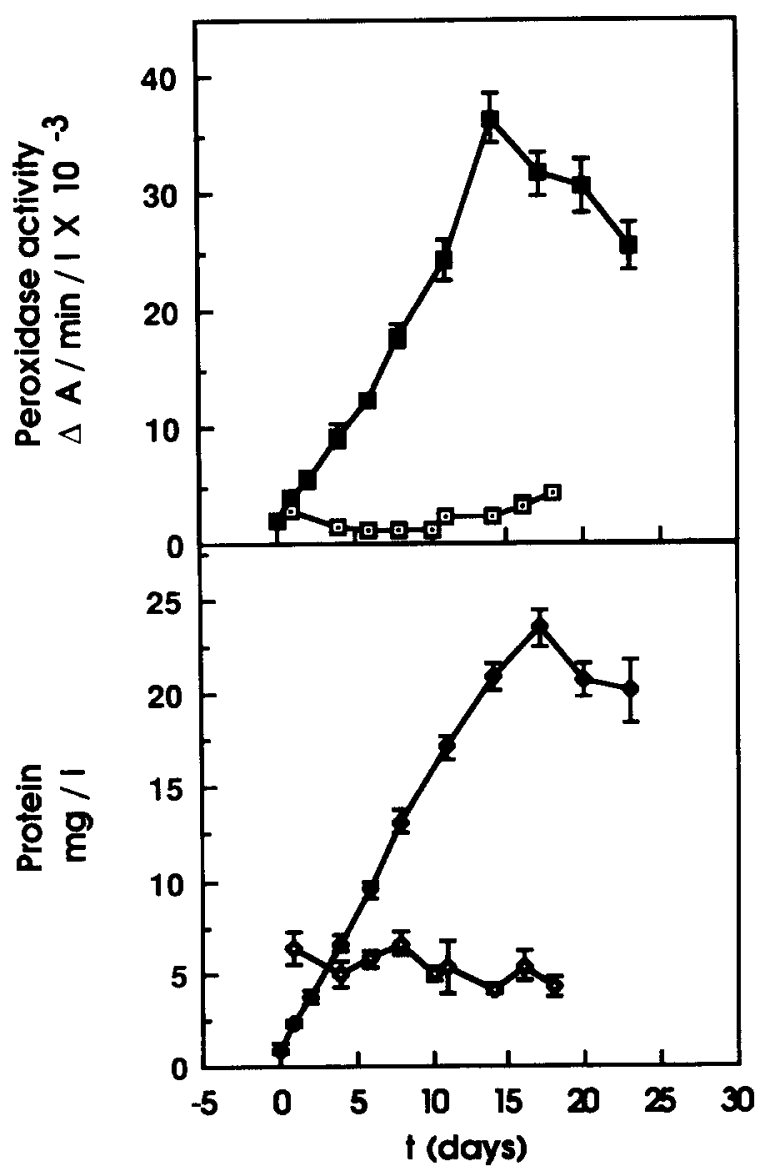

Fig. 2. The peroxidase activity and protein content of the culture filtrate of cell suspension cultures and 'hairy root' cultures Symbols are the same as in Fig. 1 Each point is the mean of at least five replicates and is shown with the standard error of the mean four nutrients in the culture filtrate of cell suspensions throughout the growth cycle are shown in Fig. 3 . This reveals that of the nutrients examined, only phosphate and carbohydrate are exhausted from the culture filtrate prior to the cessation of growth and are therefore capable of limiting growth. It must however be borne in mind that both these nutrients may be sequestered by the plant into forms that may or may not be capable of supporting further growth of the culture $[18,19]$. Ammonium is also approaching exhaustion by the end of the growth cycle and although not directly limiting growth, may quickly become limiting once the growth limitation by other nutrients is released.

The factors limiting the growth rate of cell suspension cultures are not well understood, however aeration of the cultures plays a part, and growth is related to the volumetric oxygen mass transfer coefficient $\left(k_{1} a\right)$ at low oxygenation rates [17] To

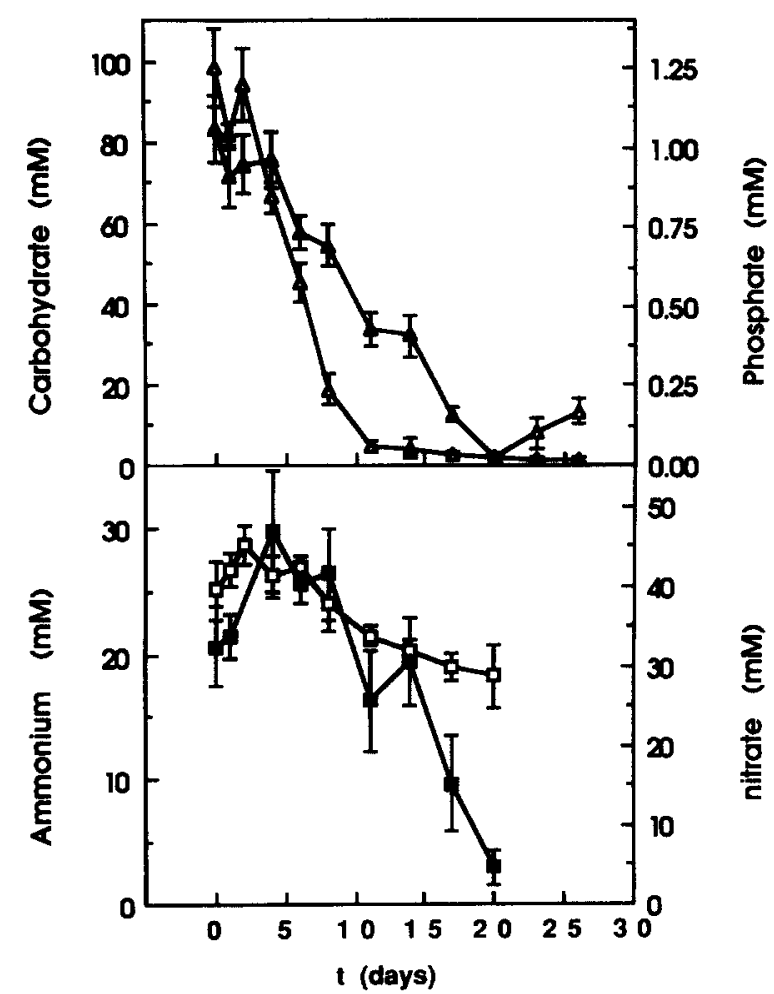

Fig. 3. The concentration of nutrients in the culture filtrate throughout the growth cycle $\Delta$ phosphate, $\Delta$ soluble carbohydrate, $\square$ nitrate, $\square$ ammonum. Note that stationary phase was reached on day 20 in these cell suspensions 
permit experimental variation of the $k_{1} a$ in shake flasks, the relationship between $\mathrm{k}_{1} \mathrm{a} / \mathrm{h}$ and culture volume in $25 \mathrm{~cm}^{3}$ Erlenmeyer flasks was established at a constant shaker speed of $110 \mathrm{rev} . / \mathrm{min}$ on an orbital shaker. Over the range $10-200 \mathrm{~cm}^{3}$ there was a linear relationship between $\log _{10} k_{1} a$ and culture volume according to the following relationship: $\log _{10} k_{1} a / h=1.8-0.00613$ culture volume $\left(\mathrm{cm}^{3}\right)$. The correlation coefficient for the relationship $(r)$ was 0.988 .

This relationship was then used to vary $k_{1} a$ in shake flasks. Growth was monitored daily by measurements of packed cell volume, and at the end of the experiment by fresh weight. The results of this experiment (shown in Fig. 4) show that the specific

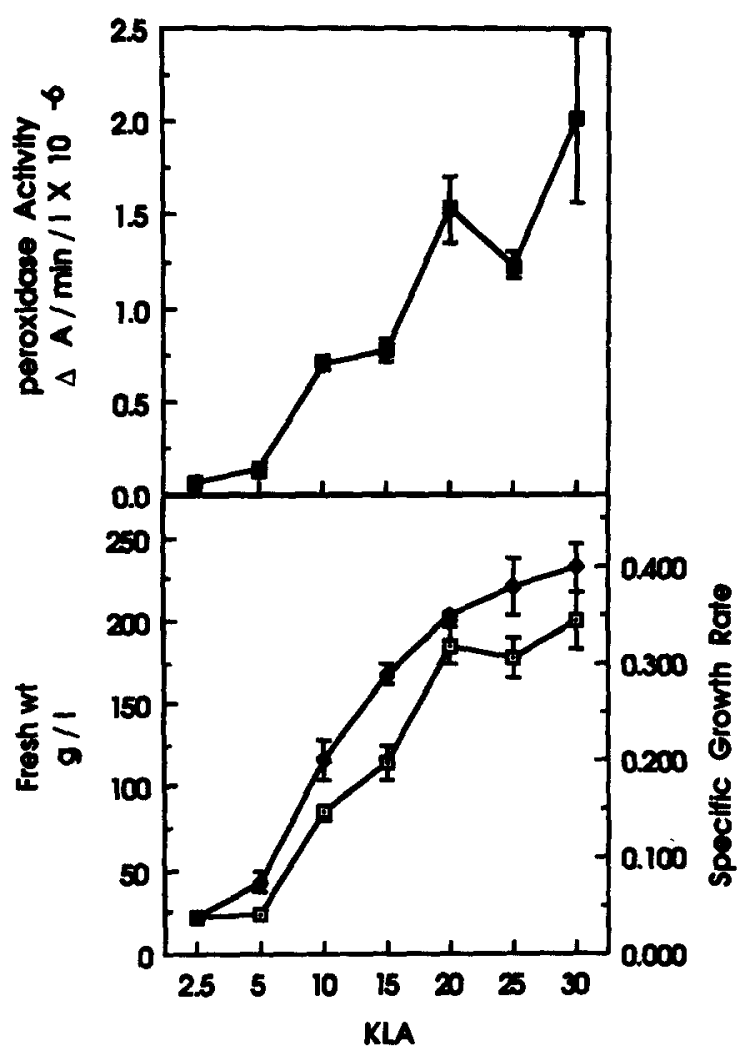

Fig. 4. The effect of the volumetnc oxygen mass transfer coefficient $\left(k_{1} a\right)$ on growth and peroxidase activity of cell suspension cultures. $(\diamond)$ specific growth rate (SGR) in exponential phase of the culture $\left(\mathrm{cm}^{3}\right.$ packcd cell volume/ $\mathrm{cm}^{3}$ packed cell volume/day), $\square$ fresh weight per litre of the culture at 1 day into stationary phase, 1 peroxadase activity of the culture per litre at 1 day into stationary phase. Each point is the mean of at least five replicates and is shown with the standard error of the mean growth rate of the cultures, the total biomass acumulation in stationary phase, and the peroxidase activity of the cultures are highly dependent on the $k_{1} a$ between $2.5 / \mathrm{h}$ and $20 / \mathrm{h}$, and hence on the rate of oxygenation of the cultures. Clearly, the rate of oxygenation of cell suspension cultures can be one of the key constraints on growth and peroxidase activity. Analysis of the specific growth rate, fresh weight, and total peroxidase activity of the cell suspensions used in the experiments into growth kinetics are all consistent with growth at a $k_{1}$ a of $12 / \mathrm{h}$. It would therefore appear that these cultures were grown under sub-optimal conditions.

The isozyme complement of these cultures is shown in Fig. 5. The enzyme from the cell extract

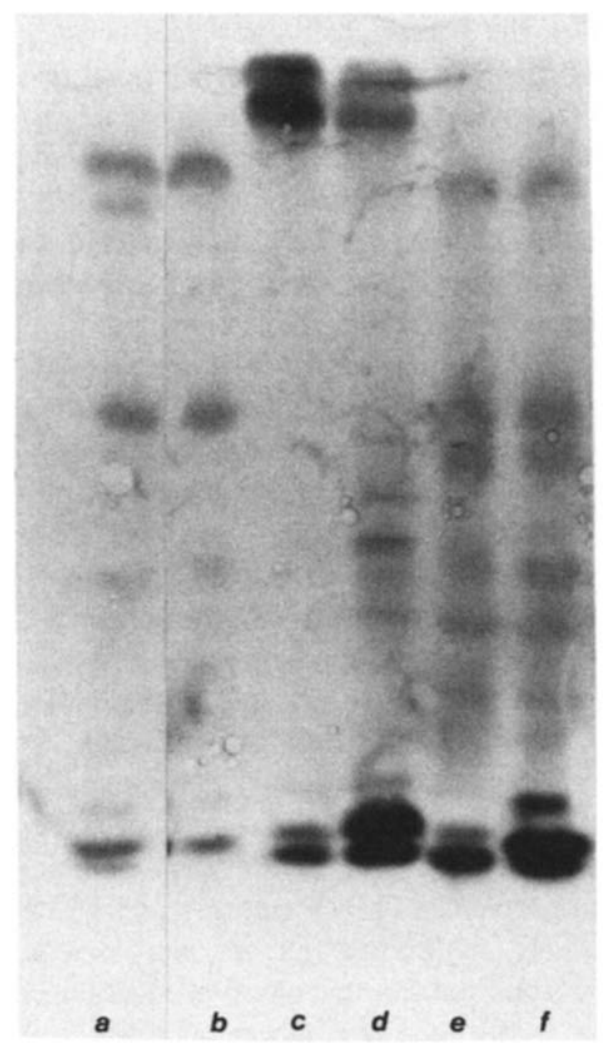

Fig. 5. A Zymogram of peroxidases obtained in culture. (a) Cathodic, isozymes (Sigma Type XII) (b) Crude horseradish peroxidase(Sigma). (c) Cell extract from cell suspension cultures (d) Culture filtrate of cell suspension cultures. (e) Cell extract from 'hairy root' cultures. (f) Culture filtrate of 'harry root' cultures. The bands are developed along a linear $\mathrm{pH}$ gradient from $\mathrm{pH} 3$ at the bottom to $\mathrm{pH} 10$ at the top. Samples and standards were diluted so that the same total peroxidase was applied per lane 
and culture filtrate of 'hairy root' cultures closely resembles that of the crude commercially available peroxidase. The enzyme from cell cultures and the culture filtrate of cell cultures contain some of the same isozymes as peroxidase from horseradish root with the addition of two extra bands at high pI.

\section{Discussion}

Both 'hairy root' and cell suspension cultures are attractive systems of culture for the production of peroxidase, although under the particular conditions of culture used in the present study, the latter were more productive in terms of total peroxıdase activity per litre of culture, peroxidase secretion into the culture filtrate, and specific activity. A more detailed investigation of the horseradish 'hairy root' system is still needed to evaluate its commercial potentral. The most fruitful line of approach would probably be enhancement of growth rate and final biomass yield since most evidence [5] suggests that 'hairy root' cultures produce similar amounts of products to roots of the intact plant, as was found for peroxidase in our cultures of horseradish.

The present report involves a more detailed evaluation of horseradish cell suspension cultures for peroxidase production. Peroxidase may be produced in cell suspension cultures to a level greatly in excess of that found in the intact plant [24]. Both callus cultures of horseradish [2] and the cell suspensions used in these experiments showed enhanced peroxidase production over roots, yet were not derived from callus cell lines which had been overtly selected for enhanced production of peroxidase, in contrast to cell suspensions reported previously [3]. Clearly, there are factors other than overt cell selection which have contributed to the increased accumulation of peroxidase in cell cultures and which may be exploited to produce further increases in yield. The reasons for the enhanced production of peroxidase in culture are not known but there are likely to be a number of contributing factors.

Undifferentiated cells proliferating in an uncontrolled manner such as callus and cell suspension cultures resemble the cells generated at wounds in many respects, and it is known that peroxidases may be specifically induced as part of a wound response to many injurious agents $[24,25]$. These cells are also in a radically different environment to th cells of the root, both in terms of their nutrier supply and in the relative size of the extracellule space and it is likely that components of the cultur medium may stimulate production. For example, th secretion of peroxidase by suspended cells is know to be under the control of the calcium concentratic in the culture filtrate [26] and the relatively hig levels of calcium supplied may increase secretic and synthesis of peroxidase. This effect will be con pounded by the greatly increased extracellular spac of cultured cells in relation to the cells of the roc and it has been suggested [2] that this may reliev feedback inhibition on enzyme production. The er ergy requirements for this active secretion are likel to be met by the abundant supply of both oxyge and carbohydrate supplied to the cultures.

It would be very advantageous from the point c commercial extraction of the enzyme to obtain it release into the culture fitrate. Extraction and pu ification of the enzyme would be simplified, and ex traction of the culture filtrate would allow conses vation of the biomass durng harvesting of th product and hence allow biomass re-use. The secre tion of peroxidase into the culture filtrate of ce suspension cultures is reported to be an active prc cess and to be regulated by the concentration c extracellular calcium [26]. There may therefore $b$ a basis for controlled secretion of a major proportio of the total peroxidase in the culture. The increase specific actıvity of the enzyme in the culture filtrat in our suspension cultures suggests that active se cretion of the enzyme must have occured, howeve I leakage of peroxidase into the culture filtrate fror dead and dying cells must also contribute to thi activity. Given that levels of viability in cell susper sion cultures may be as low as 65\% [27] and the the peroxidase present in dead and dying cells $i$ released, a considerable portion of total culture peı oxidase may be leaked into the culture filtrate. Th importance of this leakage is underlined by the fac that the proportion of peroxidase released into th culture filtrate in all studies on horseradish culture so far undertaken [1-3] is within this limit. It therefore important in experuments to investigat peroxıdase secretion that cell viability should als be examined.

These observations suggest that a number of af 
proaches may be fruitful in the maximisation of peroxidase production in cell suspension cultures of horseradish. Cell selection, ideally at the level of the individual cell, for high yielding and fast growing cell lines; optimisation of the nutrient regime to relieve nutrient limitation on growth and peroxidase synthesis; optimisation of the $\mathrm{k}_{1}$ a of the culture to maximise the specific growth rate of the culture, the peroxidase activity, and the total biomass accumulation; elicitation, to induce a controlled wound response and hence a controlled production and release of peroxidase. These investigations are currently underway in our laboratory.

\section{Acknowledgements}

The authors would like to thank EOLAS for a grant in pursuit of this research.

\section{References}

1 M. Parkinson, T. Cotter and P.J. Dix, Growth and peroxidase production in cell suspension and 'haury root' cultures of horseradish (Armoracia rusticana). Biochem. Soc. Trans., 17 (1989) 606-607.

2 B. Lotmani and J. Rabier, Induction of two callus lines (Armoracia rusticana) and their peroxadase charactensation C.R Acad Sci.Paris,t. 307(4) Serie III, (1988) 215-220.

3 Y. Yamada, S. Kobayashi, K. Watanabe and U. Hayash, Production of horseradish peroxidase by plant cell culture. Chem. Tech. Biotechnol., 38 (1987) 31-39.

$4 \mathrm{H}$ Shunsh and M. Noguch, Properties of peroxidase from Tobacco cell suspension cultures. Phytochemistry, 14 (1977) 2141-2144.

5 J.D. Hamill, A.J. Parr, M.J.C. Rhodes, R.J. Robins and N.J. Walton. New routes to plant secondary products. Bio/technology, 5 (1987) 800-804

6 T. Noda, S N. Tanaka, Y. Mano, S. Nabeshuma, H. Ohkawa and C. Matsui, Regeneration of horseradish hairy roots incited by Agrobacterum rhizogenes infection. Plant Cell Reports, 6(4) (1987) 283-28

7 T Murashige and F. Skoog, A revised medium for rapid growth and bioassays with Tobacco tissue cultures. Physiol. planta. 15 (1962) 473-497

8 H. Kamada, N. Okamura, M. Satake, H. Harada and K. Shimura, Alkalord production by harry root cultures in Atropa belladona.Plant Cell Reports, 5 (1986) 239-242

9 M Bevan, Bmary Agrobacternum vectors for plant transformation Nucl. Acid Res. 12(1984) 8711-8721.

10 L.J.W. Gilissen, C H. Hanisch ten Cate, and B. Keen, A rapid method for determining growth characteristics of plant cell populations in batch suspension cultures. Plant Cell Rep. 2(1983) 232-235.

11 E. Kay, L.M. Shannon and J.Y. Lew, Peroxidase isozymes from horseradish roots. II Catalytic properties. J. Biol. Chem., 242 (1967)2470-2473.

12 M.C. Hoyle, High resolution of peroxidase-indoleacetic isoenzymes from horseradish by isoelectric focusing. Plant Physiol., 60 (1977) 787-793.

13 J Clarke and L.M Shannon,. The isolation and charactensation of the glycopeptides from horseradish peroxidase isozyme C. Biochum. Biophys. Acta, (1976) 428-442.

14 C.H. Fiske and Y. SubbaRow, The colorumetric determination of phosphorus. J. Biol. Chem., 66 (1925) 375.

15 A.I. Vogel, A Textbook of Quantitative Inorganic Analysis. Longmans 1986, Chsp X, pp. 783-784

16 D J.D. Nicholas and A. Nason, Determination of nitrate and ammonia. Brucine method for nitrate. Methods Enzymol. 1 (1957) 981-984

17 A. Kato, Y. Shumızu and S. Nagas, Effect of initıal kla on the growth of Tobacco cells in batch culture. J Ferment. Technol, 53 (1975) 744-751.

18 K.-H Knobloch, G. Beutnagel and J Berlin, Influence of accumulated phosphate on culture growth and formation of connamoyl putrescines in medum-induced cell suspension cultures of Nicotiana tabacum cultivar Xanthii. Planta, 153 (1981) 582-585.

19 A. Nato, S Bazetoux and Y. Matheu, Photosynthetic capacties and growth charactenstics of Nicotiana tabacum (C.V. Xanthii) cell suspension cultures. Physiologia Plantarum, 41 (1977) 116-123.

20 I.A. Veliky, Effect of $\mathrm{pH}$ on tryptophol formation by cultured Ipomoea sp plant cells. Lloydia, 40 (1977) 482-486.

21 J.J McCarthy, D. Ratcliffe and H.E Street, The effect of nutrient medium composition on the growth cycle of Catharanthus roseus $\mathrm{G}$ Don cells grown in batch cultuct. J. Exp. Bot., 31(1980) 1315-1325

22 M.E. Davies, Polyphenol synthesis in cell suspension cultures of Paul's Scarlet rose. Planta, 104 (1972) 50-65.

23 D.T. Nash, and M.E. Davies, Some aspects of growth and metabolssm of Paul's Scarlet Rose cell suspensions. J Exp. Bot., 23 (1972) 75-79.

24 M.P. Robbins, G.P. Boldwell and R.A. Dixon, Metabolic changes in elicitor-treated bean cells. Selectivity of enzyme induction in relation to phytoalexin accumulation. Eur. J. Biochem. 148 (1985) 571-578.

25 A.G. Endress, S.J. Suarez, and A.C. Taylor, Peroxidase activity in plant leaves exposed to gaseous $\mathrm{HCI}$ or ozone. Environ. Pollut. Ser. A., 22 (1980) 47-58

26 L. Stıcher, C. Penel and H. Greppin, Calcuum requirement for secretion of peroxidase by plant cell suspensions J. Cell Sc. 48 (1981) 345-353

27 W.F Fett and R.M. Zacharius, Bacterial growth and phytoalexun elicitation in soybean cell suspension cultures inoculated with Pseudomonas syringae pathovars. Physiol. Plant Pathol 22(1983) 151-172. 